\title{
Analysis of Bulk Metallic Glass Formation Using a Tetrahedron Composition Diagram that Consists of Constituent Classes Based on Blocks of Elements in the Periodic Table
}

\author{
Akira Takeuchi ${ }^{1}$, Budaraju Srinivasa Murty ${ }^{2}$, Masashi Hasegawa ${ }^{1}$, \\ Srinivasa Ranganathan ${ }^{3}$ and Akihisa Inoue ${ }^{1}$ \\ ${ }^{1}$ Institute for Materials Research, Tohoku University, Sendai 980-8577, Japan \\ ${ }^{2}$ Department of Metallurgical and Materials Engineering, Indian Institute of Technology, \\ Madras, Chennai 600 036, India \\ ${ }^{3}$ Department of Metallurgy, Indian Institute of Science, Bangalore 560 012, India
}

The formation of bulk metallic glasses (BMGs) has been analyzed with a tetrahedron composition diagram, which is comprised of constituent classes from blocks of elements in the periodic table. When $\mathrm{Al}$ and $\mathrm{Ga}$ are involved in the BMG composition environment, they are assumed to correspond to either s- or p-block elements. The analysis under the assumption reveals the presence of a composition band that connects the composition regions over different classes of BMGs. The diagram has a topological simplicity, is applicable to any multicomponent alloy system, and can be analyzed from the bonding nature of the atomic pairs. Thus, this diagram is an important tool for analyzing and developing BMGs. [doi:10.2320/matertrans.MF200604]

(Received October 11, 2006; Accepted November 28, 2006; Published May 25, 2007)

Keywords: bulk amorphous materials, metallic glasses, liquids, electronic structure

\section{Introduction}

Recently, bulk metallic glasses (BMGs) have received increasing attention in the field of non-equilibrium metallic materials because metallic glasses have been successfully fabricated in bulk shapes, which were a couple of millimeters or more. ${ }^{1)}$ Because metallic glasses and BMGs are in a nonequilibrium state, there is a minimum cooling rate necessary to form the glassy phase when they are produced from a liquid. The critical cooling rate to form BMGs from a liquid is on the order of $100 \mathrm{~K} \cdot \mathrm{s}^{-1}$ or less, which is much slower than that of metallic glasses, which is on the order of $10^{6} \mathrm{~K} \cdot \mathrm{s}^{-1}$ or more. BMGs can be produced in a bulk form due to the low critical cooling rate, which is close to the cooling rate required to form crystalline alloys in an equilibrium state. The formation of metallic glasses and BMGs from a liquid is related to the stabilization of the liquid phase, which is accompanied by the presence of an eutectic reaction in the alloy system.

Metallic glasses and BMGs have been discovered by selecting appropriate combinations of constituents for alloy systems and subsequently finding the appropriate alloy compositions to form a glassy phase in a solid state. In other words, metallic glasses and BMGs have been developed by finding alloy systems with a eutectic reaction and an alloy composition near where the eutectic reaction occurs. The appropriate combinations and fractions of the constituents have been reported as the classification of metallic glasses and BMGs. For instance, Hafner ${ }^{2}$ has classified the glassforming binary metallic systems into six classes, T-M, S-S, ST, S-R, T-R and T-T, based on the chemical nature of their constituents where $\mathrm{S}, \mathrm{T}, \mathrm{R}$, and $\mathrm{M}$ are abbreviations for simple metal, transition metal, rare-earth metal, and metalloid, respectively. Masumoto ${ }^{3)}$ has focused on the periodic table to show that there are important combinations of metal- metal and metal-metalloid constituents that form amorphous alloys by a rapid-quenching technique.

Inoue $^{4)}$ has extended this classification concept. In 2000, he classified BMGs into five classes according to the chemical species and atomic size differences of the constituents. In 2005, Takeuchi and Inoue ${ }^{5)}$ modified this BMG classification $^{4)}$ by considering an additional factor, which is the period of the elements in the periodic table. They classified BMGs into seven classes; ${ }^{5)}$ the new classes of BMGs are represented by $\mathrm{Cu}-\mathrm{Ti}-\mathrm{Zr}$ and $\mathrm{Ca}-\mathrm{Mg}-\mathrm{Zn}$ BMGs, which were discovered between 2000 and 2005, have been added to the five original classes previously reported. ${ }^{4)}$ Besides the studies mentioned above, analyses on BMG formation have also been conducted using a topology approach $^{6)}$ and a Mendeleev number approach ${ }^{7)}$ based on the concept of a Pettifor Map. ${ }^{8)}$

Current researchers have treated the constituent classes of BMGs differently. For instance, $\mathrm{Sn}$ has been assigned to the constituent class of (Al, Ga, Sn) in one study, ${ }^{4}$ but in another study assigned $\mathrm{Sn}$ to a different constituent class. ${ }^{5)}$ On the other hand, Miracle ${ }^{6)}$ and Ranganathan et al. ${ }^{7)}$ treated $\mathrm{Mg}$ as a different constituent from $\mathrm{Ca}$, which differs from the chemistry approach of the previous studies of the present authors. $^{4,5)}$ These constituent class differences suggest that the classification of BMG systems should consider supplemental factors in order to complete the classification series of BMGs. Accordingly, the present report focuses on supplemental factors, which include the characteristics of the electrons (electron configuration and electronegativity), because these characteristics are related to the periodic table, which is the origin of the chemistry approach. In addition, the supplemental factors may also be useful for determining general trends in the composition regions of BMGs. This approach should be useful in determining the composition criteria, which has yet to be established, necessary to analyze 
Table 1 Constituent classes used to classify metallic glasses ${ }^{2,3}$ and $\mathrm{BMGs}^{4,5)}$ in previous studies. Constituent classes in the same vertical row show a similar relationship to those observed in other studies.

\begin{tabular}{|c|c|c|c|c|c|}
\hline \multicolumn{5}{|c|}{ Class of constituents } & ference \\
\hline $\mathrm{S}(\mathrm{Al})$ & S & $\mathrm{T}, \mathrm{R}$ & $\mathrm{T}$ & M & 2) \\
\hline - & Metal & Metal & Metal & Metalloid & 3) \\
\hline $\mathrm{Al}, \mathrm{Ga}, \mathrm{Sn}$ & Simple Metal & ETM,Ln & LTM & Metalloid & 4) \\
\hline $\mathrm{Al}, \mathrm{Ga}$ & IIA & ETM,Ln & LTM,BM & Metalloid & 5) \\
\hline
\end{tabular}

S: simple metal, T: transition metal, R: rare-earth metal, M: metalloid Simple Metal: Be, Mg, ETM: early transition metal (IIIA-VIA), LTM: late transition metal (VIII-IIB), Ln: lanthanide metal, Metalloid: nonmetal

IIA: IIA group element, BM: IIIB-VIIB metallic element

BMG formation because only a few studies have been separately conducted for Ca-based ${ }^{7)}$ and Zr-based BMGs. ${ }^{9)}$ The latter study was based on conduction electron concentration.

The purposes of the present study are to classify BMGs based on the constituent class, which is categorized from chemical and electronic points of view, and to identify BMGs in terms of their alloy composition regions and alloy systems.

\section{Procedure}

This study uses two different classes. One is a class of BMG systems and the other is a constituent class where the class indicates a set in mathematical terms, and the constituents indicate the components of the alloy in a free atom state. It is noted that the former is the class of alloys, whereas the latter is the class of atoms. The analysis was conducted using the following procedure. The constituents of the alloys and the constituent class were initially considered. Then the class of the BMG system was addressed by considering the combinations of constituent classes instead of combinations of the alloy constituents. Accordingly, the class, group, components, and other terms used in the present study do not deal with local atomic arrangements.

Table 1 summarizes the constituent class used to classify the metallic glasses and the BMGs in the previous studies. ${ }^{2-5}$ ) The metallic glasses can be formed by selecting constituents from a couple of constituent classes. For instance, the appropriate combinations of constituents from four classes of constituents, $\mathrm{S}, \mathrm{T}, \mathrm{R}$, and $\mathrm{M}$, yield six classes of metallic glasses, which are T-M, S-S, S-T, S-R, T-R, and T-T types. ${ }^{2)}$ An example of a metallic glass and its composition for each class of the glass-forming binary metallic system has been reported ${ }^{2)}$ as $\mathrm{Pd}_{80} \mathrm{Si}_{20}$ for T-M, $\mathrm{Mg}_{70} \mathrm{Zn}_{30}$ for $\mathrm{S}-\mathrm{S}, \mathrm{Ca}_{65} \mathrm{Pd}_{35}$ for $\mathrm{S}-\mathrm{T}, \mathrm{La}_{70} \mathrm{Al}_{30}$ for $\mathrm{S}-\mathrm{R}, \mathrm{Gd}_{67} \mathrm{Co}_{33}$ for $\mathrm{T}-\mathrm{R}$, and $\mathrm{Nb}_{60} \mathrm{Ni}_{40}$ for T-T. On the other hand, two constituent classes of metals and metalloids yield the metal-metal and metal-metalloid classes of metallic glasses. ${ }^{3)}$ Similarly, the constituents from five constituent classes, (1) Simple Metal, (2) Early Transition Metal (ETM) and Lanthanide Metal (Ln), (3) Late Transition Metal (LTM), (4) aluminium-gallium-tin (Al, Ga, $\mathrm{Sn}$ ), and (5) Metalloid, have been reported by Inoue $^{4)}$ to give five BMG classes. Here, these five constituent classes contain the following elements: (1) $\mathrm{Be}$ and $\mathrm{Mg}$, (2) IIIA-VIIA elements and La to Lu, (3) VIII-IIB elements, (1) (5) B, C, Si,
Table 2 Some constituents for forming BMGs listed along with the constituent classes used in the present study and the period in the periodic table.

\begin{tabular}{ccccc}
\hline \multirow{2}{*}{$\begin{array}{c}\text { Period in the } \\
\text { periodic table }\end{array}$} & \multicolumn{4}{c}{ Class of constituents } \\
\cline { 2 - 5 } & $\mathrm{s}$ & $\mathrm{d}_{\mathrm{E}} \mathrm{f}$ & $\mathrm{d}_{\mathrm{L}} \mathrm{p}$ & $\mathrm{p}$ \\
\hline 2 & $\mathrm{Be}$ & - & - & $\mathrm{B}, \mathrm{C}$ \\
3 & $\mathrm{Mg}, \mathrm{Al}^{* 1}(\mathrm{~s})$ & - & $\mathrm{Al}^{* 2}(\mathrm{p})$ & $\mathrm{Si}, \mathrm{P}$ \\
4 & $\mathrm{Ca}, \mathrm{Ga}^{* 1}(\mathrm{~s})$ & $\mathrm{Ti}$ & $\mathrm{Fe}, \mathrm{Ni}, \mathrm{Cu}, \mathrm{Zn}, \mathrm{Ga}^{* 2}(\mathrm{p})$ & $\mathrm{Ge}$ \\
5 & - & $\mathrm{Y}, \mathrm{Zr}$ & - & - \\
6 & - & $\mathrm{La}$ & - & - \\
\hline
\end{tabular}

${ }^{* 1}(\mathrm{~s}),{ }^{* 2}(\mathrm{p})$ : Assumed to be a constituent, which is in the $\mathrm{s}-$ or $\mathrm{d}_{\mathrm{L}} \mathrm{p}$-class, respectively.

$\mathrm{P}$, and Ge. Inoue ${ }^{4)}$ has reported representative BMG systems for each BMG class as (C-1) (ETM,Ln)-(Al,Ga,Sn)-LTM exemplified by La-Al-Ni, (C-2) (LTM)-(ETM,Ln)-Metalloid by $\mathrm{Fe}-\mathrm{Zr}-\mathrm{B}$, (C-3) (LTM)-(Al,Ga,Sn)-Metalloid by Fe(Al,Ga)-(P,C,B), (C-4) Simple Metal-LTM-(ETM,Ln) by $\mathrm{Mg}-\mathrm{Cu}-\mathrm{Y}$, and (C-5) LTM-Metalloid by Pd-Ni-P BMG systems. Here, the symbol "C" in C-1 to C-5 designates the abbreviation of the class of the BMG system. In addition, the classification of BMGs reported by Takeuchi and Inoue ${ }^{5)}$ that modify the constituent classes, Simple Metal and LTM, in a previous study ${ }^{4}$ to IIA and (LTM, BM), respectively, gives the seven classes of BMG systems where IIA is a IIA group element and BM is a IIIB-VIIB metallic element, which are both from the periodic table. The seven classes of BMG systems reported by Takeuchi and Inoue ${ }^{5)}$ consist of five classes of BMG systems, which correspond to the previous results by Inoue ${ }^{4)}$ and two new classes of BMG systems. The two classes of BMG systems are (C-6) LTM-(ETM,Ln), which is represented by $\mathrm{Cu}-\mathrm{Zr}-\mathrm{Ti}$, and (C-7) IIA-(LTM,BM), which is represented by $\mathrm{Ca}-\mathrm{Mg}-\mathrm{Zn}$. Table 1 shows that the constituent class is determined on the basis of the groups in the periodic table, which is the key to the chemical approach for classifying BMGs.

Table 2 summarizes some of the constituents used to form BMGs, which are listed in accordance with the constituent classes used in the present study and the period in the periodic table. The constituent classes in Table 2 are $s, d_{E} f$, $\mathrm{d}_{\mathrm{L}} \mathrm{p}$, and $\mathrm{p}$, whose symbols are determined by the abbreviations of s-, d-, f-, and p-blocks in the periodic table and early (E) and late (L) transition metals, which contain elements of IIIA-VIIA and VIII to IIB elements, respectively. It should be noted that the lower-case s- is different from the capital $\mathrm{S}$ used in the previous study ${ }^{2)}$ because s- and others (d-, f-, and p-) are due to the outer electronic configuration of the elements. The classes of s- and p-mostly correspond to those of IIA and Metalloid in Table 1, respectively, and the latter was used in our previous study. ${ }^{5)}$ Furthermore, the classes of $d_{E} f$ and $d_{L} p$ mostly correspond (2) to ETM,Ln and $\mathrm{LTM}_{\mathrm{B}} \mathrm{BM}^{5)}$ in Table 1 , respectively, where BM indicates IIIB-VIIB metallic elements.

In Table 2 we assume that $\mathrm{Al}$ and $\mathrm{Ga}$ can be constituents in either the $\mathrm{s}$ - or $\mathrm{d}_{\mathrm{L}} \mathrm{p}$-constituent class $\left(\mathrm{Al}^{*}(\mathrm{~s})\right.$ or $\mathrm{Al}^{* *}(\mathrm{p})$, $\mathrm{Ga}^{*}(\mathrm{~s})$ or $\left.\mathrm{Ga}^{* *}(\mathrm{p})\right)$ and that the class depends on the compositional environment of the BMG. The validity of this assumption is discussed in Section 4. With this assumption, the constituent classes used to form BMGs and their 


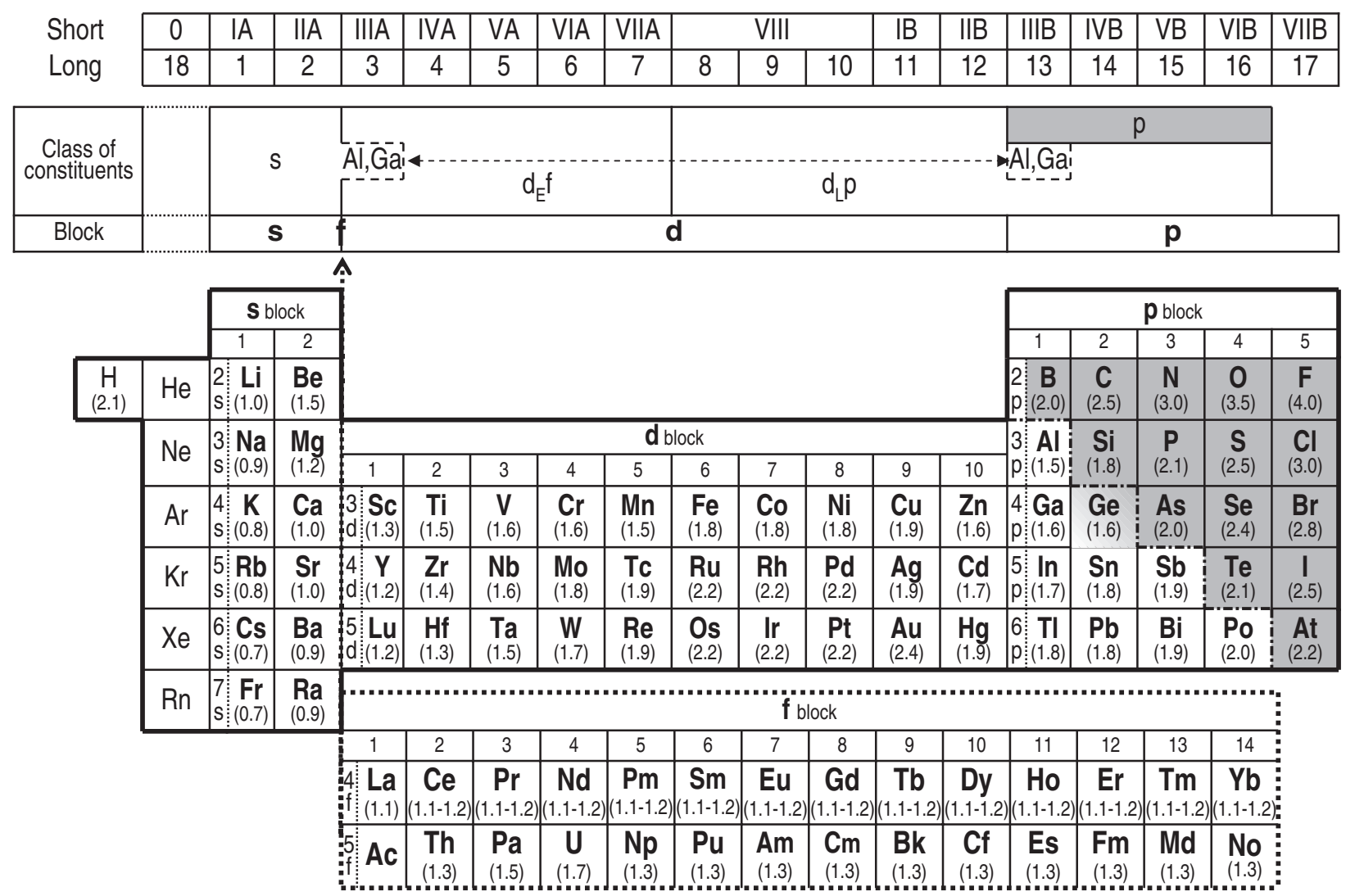

Fig. 1 Relationships of the components and blocks of elements used for classifications, summarized in the periodic table quoted from the literature, ${ }^{36)}$ excluding hydrogen $(\mathrm{H})$ from the other elements. Non-metallic elements, including metalloids, are hatched. Germanium (Ge) is regarded as a metallic element in the literature, ${ }^{36)}$ but is treated as a metalloid in the present study. The value beneath the atomic symbol in parenthesis is the electronegativity ${ }^{34)}$ given by Pauling. Aluminum (Al) and gallium (Ga) are treated as constituents of either the s- or $\mathrm{d}_{\mathrm{L}} \mathrm{p}$-constituent class.

constituents, which are $\mathrm{s}\left(\mathrm{Be}, \mathrm{Mg}, \mathrm{Al}^{*}(\mathrm{~s}), \mathrm{Ca}, \mathrm{Ga}^{*}\right), \mathrm{d}_{\mathrm{E}} \mathrm{f}(\mathrm{Ti}, \mathrm{Y}$, $\mathrm{Zr}, \mathrm{La}), \mathrm{d}_{\mathrm{L}} \mathrm{p}\left(\mathrm{Al}^{* *}(\mathrm{p}), \mathrm{Fe}, \mathrm{Ni}, \mathrm{Cu}, \mathrm{Zn}, \mathrm{Ga}^{* *}(\mathrm{p})\right)$, and $\mathrm{p}(\mathrm{B}, \mathrm{C}, \mathrm{Si}, \mathrm{P}$, $\mathrm{Ge})$, are shown in Table 2 . The present study was analyzed based on the constituent classes shown in Table 2 and by referring to our previous studies ${ }^{4,5}$ for the seven classes of BMGs: C-1 (Zr- and La-based $\left.{ }^{10-14)}\right), \mathrm{C}-2$ (Fe-based $\left.{ }^{15,16)}\right)$, C3 (Fe-based multicomponent $\left.{ }^{17,18}\right)$, C-4 (Mg-based $^{19,20)}$ ), C-5 (Pd- and Pt-based ${ }^{21-23)}$ ), C-6 (LTM-based ${ }^{24-30)}$ ), and C-7 (Cabased $^{31-33)}$ ) BMGs. Figure 1 illustrates the relationships of the constituent class and the four blocks (s, d, f, and p) of elements in the periodic table along with the electronegativity $(\chi),{ }^{34)}$ which is used in the discussion in Section 4.

\section{Results}

Figure 2 illustrates the classification of BMGs based on the constituent classes of s-, $d_{E} f-, d_{L} p-$, and p-determined in Table 2. The constituent classes $\left(\mathrm{s}_{-}, \mathrm{d}_{\mathrm{E}} \mathrm{f}_{-}, \mathrm{d}_{\mathrm{L}} \mathrm{p}-\right.$, and $\mathrm{p}-$ ) are drawn with big circles, while the BMG system classes (C-1 to C-7) are drawn with small circles. The triangles hatches are to distinguish the area. The class of the BMG systems and the combinations of constituent classes to form BMGs are also tabulated in Fig. 2. The arrows in Fig. 2 indicate the minimum combination of constituent classes necessary to form each BMG system (3). Table 3 describes the details.

Table 3 shows the class of the BMG system, a representative alloy system, and the principal constituents, which are summarized by the constituent class. The status of $\mathrm{Al}$ and $\mathrm{Ga}$ is determined in order to ensure that the results are within the framework of the present studies ${ }^{4,5)}$ as discussed in Section 4. Table 3 shows that a $\mathrm{Zr}-\mathrm{Al}-\mathrm{Ni}$ ternary BMG, which belongs to $\mathrm{C}-1$, can be formed using $\mathrm{Zr}, \mathrm{Al}^{*}(\mathrm{~s})$, and $\mathrm{Ni}$ from the $\mathrm{d}_{\mathrm{E}} \mathrm{f}-$, $\mathrm{s}-$, and $\mathrm{d}_{\mathrm{L}} \mathrm{p}$-constituent classes, respectively. It is noted that $\mathrm{Al}^{*}(\mathrm{~s})$ in $\mathrm{Zr}-\mathrm{Al}-\mathrm{Ni}(\mathrm{C}-1)$ is regarded as a constituent of the sclass. Similarly, a Zr-Ti-Ni-Cu-Be quinary BMG also belongs to $\mathrm{C}-1$ because both $\mathrm{Zr}$ and $\mathrm{Ti}$ are constituents in the $\mathrm{d}_{\mathrm{E}} \mathrm{f}$-class, while both $\mathrm{Ni}$ and $\mathrm{Cu}$ are in the $\mathrm{d}_{\mathrm{L}} \mathrm{p}$-class, and $\mathrm{Be}$ is in the s-class. These examples reveal that the minimum number of constituent classes is three ( $\left(\mathrm{s}-, \mathrm{d}_{\mathrm{E}} \mathrm{f}-, \mathrm{d}_{\mathrm{L}} \mathrm{p}-\right)$ and that these BMGs are classified as Zr-based BMGs. In addition, three constituent classes are necessary to form BMGs in BMG systems that in classes 1 to 4 (C-1 to C-4). However, only two constituent classes are required to form BMGs in BMG system classes 5 to 7 (C-5 to C-7). For instance, Pd-Ni$\mathrm{P}$ BMG belongs to $\mathrm{C}-5$ and consists of two constituent classes because both $\mathrm{Pd}$ and $\mathrm{Ni}$ belong to the $\mathrm{d}_{\mathrm{L}} \mathrm{p}$-constituent class and $\mathrm{P}$ belongs the p-class. (4) It is important to note that in the present classification Be-containing Zr-based BMGs ${ }^{13,14)}$ are in the same BMG system class (C-1) with Al-containing $\mathrm{Zr}$ based BMGs, ${ }^{11,12)}$ which is completely different from previous results ${ }^{4,5)}$ where Be-containing $\mathrm{Zr}$-based and $\mathrm{Mg}$ based BMGs are classified as C-4. This discrepancy is because $\mathrm{Be}$ and $\mathrm{Al}$ were not in the same constituent class in the previous studies. 


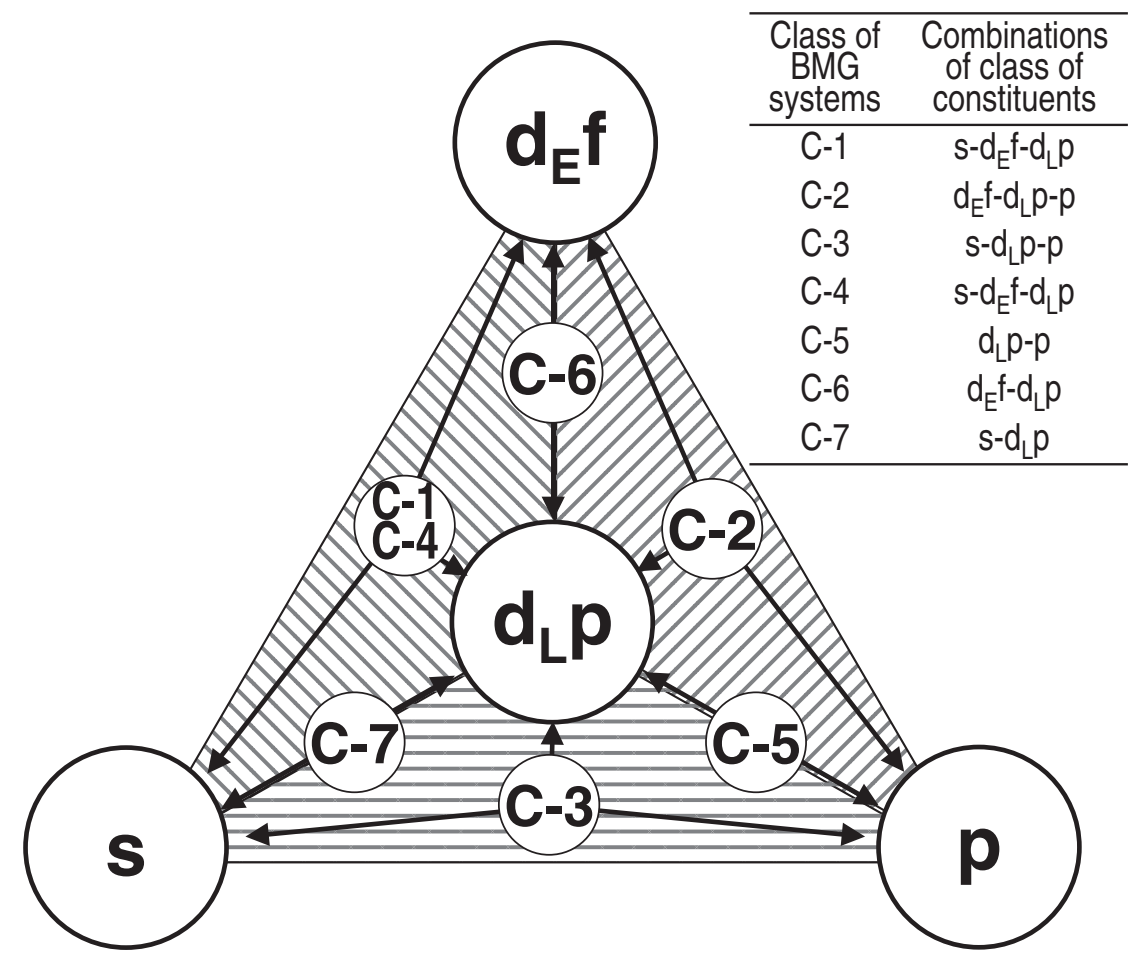

Fig. 2 Classification of metallic glasses based on the constituent classes of the s-block elements (s), early transition metals and f-block elements $\left(d_{E} f\right)$, late transition and p-block metals $\left(d_{L} p\right)$ and metalloids $(p)$. The numbers in the circles designate the number of BMG classes (C-1 to $\mathrm{C}-7$ ), which corresponds to those in our previous study. ${ }^{5}$ ) The class of the BMG systems and the combinations of constituent classes for each class of the BMG system are tabulated together.

Table 3 Class of the BMG system, representative alloy system, and principal constituents summarized by the constituent class. Atomic symbols in bold are the main constituent in each alloy system.

\begin{tabular}{|c|c|c|c|c|c|}
\hline \multirow{2}{*}{$\begin{array}{c}\text { Class of } \\
\text { BMG system }\end{array}$} & \multirow{2}{*}{$\begin{array}{l}\text { Representative } \\
\text { system }\end{array}$} & \multicolumn{4}{|c|}{ Class of constituents } \\
\hline & & $\mathrm{s}$ & $d_{E} f$ & $\mathrm{~d}_{\mathrm{L}} \mathrm{p}$ & $\mathrm{p}$ \\
\hline \multirow{2}{*}{$\mathrm{C}-1$} & $\mathrm{Zr}-\mathrm{Al}-\mathrm{Ni}$ & $\mathrm{Al}^{* 1}(\mathrm{~s})$ & $\operatorname{Zr}(\mathbf{L a})$ & $\mathrm{Ni}, \mathrm{Cu}$ & - \\
\hline & $\mathrm{Zr}-\mathrm{Ti}-\mathrm{Ni}-\mathrm{Cu}-\mathrm{Be}$ & $\mathrm{Be}$ & $\mathbf{Z r}, \mathrm{Ti}$ & $\mathrm{Ni}, \mathrm{Cu}$ & - \\
\hline $\mathrm{C}-2$ & $\mathrm{Fe}-\mathrm{Zr}-\mathrm{B}$ & - & $\mathrm{Zr}$ & $\mathbf{F e}$ & B \\
\hline $\mathrm{C}-3$ & $\mathrm{Fe}-(\mathrm{Al}, \mathrm{Ga})-(\mathrm{P}, \mathrm{B}, \mathrm{C})$ & $\mathrm{Al}^{* 1}(\mathrm{~s}), \mathrm{Ga}^{* 1}(\mathrm{~s})$ & - & $\mathrm{Fe}$ & $\mathrm{B}, \mathrm{C}, \mathrm{P}, \mathrm{Si}, \mathrm{Ge}$ \\
\hline \multirow[t]{2}{*}{$\mathrm{C}-5$} & Pd-Ni-P & - & - & Pd,Ni & $\mathrm{P}$ \\
\hline & $\mathrm{Cu}-\mathrm{Zr}-\mathrm{Ti}$ & - & $\mathrm{Ti}, \mathrm{Z}$ & $\mathbf{C u}$ & - \\
\hline \multirow[t]{3}{*}{ C-6 } & $\mathrm{Cu}-\mathrm{Zr}-\mathrm{Ga}$ & - & $\mathrm{Zr}$ & $\mathbf{C u}, \mathrm{Ga}^{* 2}(\mathrm{p})$ & - \\
\hline & $\mathrm{Cu}-\mathrm{Hf}-\mathrm{Al}$ & - & Hf & $\mathbf{C u}, \mathrm{Al}^{* 2}(\mathrm{p})$ & - \\
\hline & $\mathrm{Ca}-\mathrm{Mg}-\mathrm{Cu}$ & $\mathbf{C a}(\mathrm{Mg})$ & - & $\mathrm{Cu}$ & - \\
\hline $\mathrm{C}-7$ & $\mathrm{Ca}-\mathrm{Mg}-\mathrm{Zn}$ & $\mathbf{C a}(\mathrm{Mg})$ & - & $\mathrm{Zn}$ & - \\
\hline
\end{tabular}

${ }^{* 1}(\mathrm{~s}),{ }^{* 2}(\mathrm{p})$ : Assumed to be either a s- or $\mathrm{d}_{\mathrm{L}} \mathrm{p}$-class of constituent, respectively.

Table 4 shows the BMG system class, the alloy system, the alloy composition with reference number, and the $s-d_{E} f-d_{L} p-$ $p$ description of the alloy composition for representative BMGs. The alloy composition listed in Table 4 is rewritten as the $s-d_{E} f-d_{L} p-p$ descriptions in order to use the $s-d_{E} f-d_{L} p-p$ description in the composition diagram. For instance, $\mathrm{La}_{55} \mathrm{Al}_{25} \mathrm{Ni}_{20}$, which is in $\mathrm{C}-1$, is described as $\left(\mathrm{d}_{\mathrm{E}} \mathrm{f}\right)_{55} \mathrm{~S}_{25}-$ $\left(\mathrm{d}_{\mathrm{L}} \mathrm{p}\right)_{20}$, indicating that $\mathrm{La}, \mathrm{Al}$, and $\mathrm{Ni}$ correspond to $\mathrm{d}_{\mathrm{E}} \mathrm{f}-\mathrm{s}-$, and $\mathrm{d}_{\mathrm{L}} \mathrm{p}$-constituent classes, respectively. Similarly, $\left(\mathrm{Zr}_{41.2^{-}}\right.$ $\left.\mathrm{Ti}_{13.8}\right) \mathrm{Be}_{22.5}\left(\mathrm{Cu}_{12.5} \mathrm{Ni}_{10.0}\right)$ in $\mathrm{C}-1$ is described as $\left(\mathrm{d}_{\mathrm{E}} \mathrm{f}\right)_{55} \mathrm{~S}_{22.5^{-}}$
$\left(\mathrm{d}_{\mathrm{L}} \mathrm{p}\right)_{22.5}$, which indicates that $\mathrm{Zr}$ and $\mathrm{Ti}$ belong to $\mathrm{d}_{\mathrm{E}} \mathrm{f}-, \mathrm{Be}$ to s-, and $\mathrm{Cu}$ and $\mathrm{Ni}$ to $\mathrm{d}_{\mathrm{L}} \mathrm{p}$ - . As exemplified by $\left(\mathrm{Zr}_{41.2^{-}}\right.$ $\left.\mathrm{Ti}_{13.8}\right) \mathrm{Be}_{22.5}\left(\mathrm{Cu}_{12.5} \mathrm{Ni}_{10.0}\right)$ BMG, the parentheses are used for alloy composition that are in the same constituent class. Table 4 sums the resultant compositions with respect to each constituent class. Furthermore, the order of the atomic symbol and its composition in the alloy composition in Table 4 are changed from the original reference in order to maintain consistency with the $s-d_{E} f-d_{L} p-p$ description of each alloy system. 
Table 4 Class of BMG system, alloy system, alloy composition with reference number, and s-d $\mathrm{d}_{\mathrm{E}} \mathrm{f}-\mathrm{d}_{\mathrm{L}} \mathrm{p}-\mathrm{p}$ description of the alloy composition for representative BMGs. The $s-d_{E} f-d_{L} p-p$ descriptions of the alloy compositions change from the alloy compositions listed in the third row in Table 4 in order to simplify the $s-d_{E} f-d_{L} p-p$ description with respect to the points of the order of symbol and its composition.

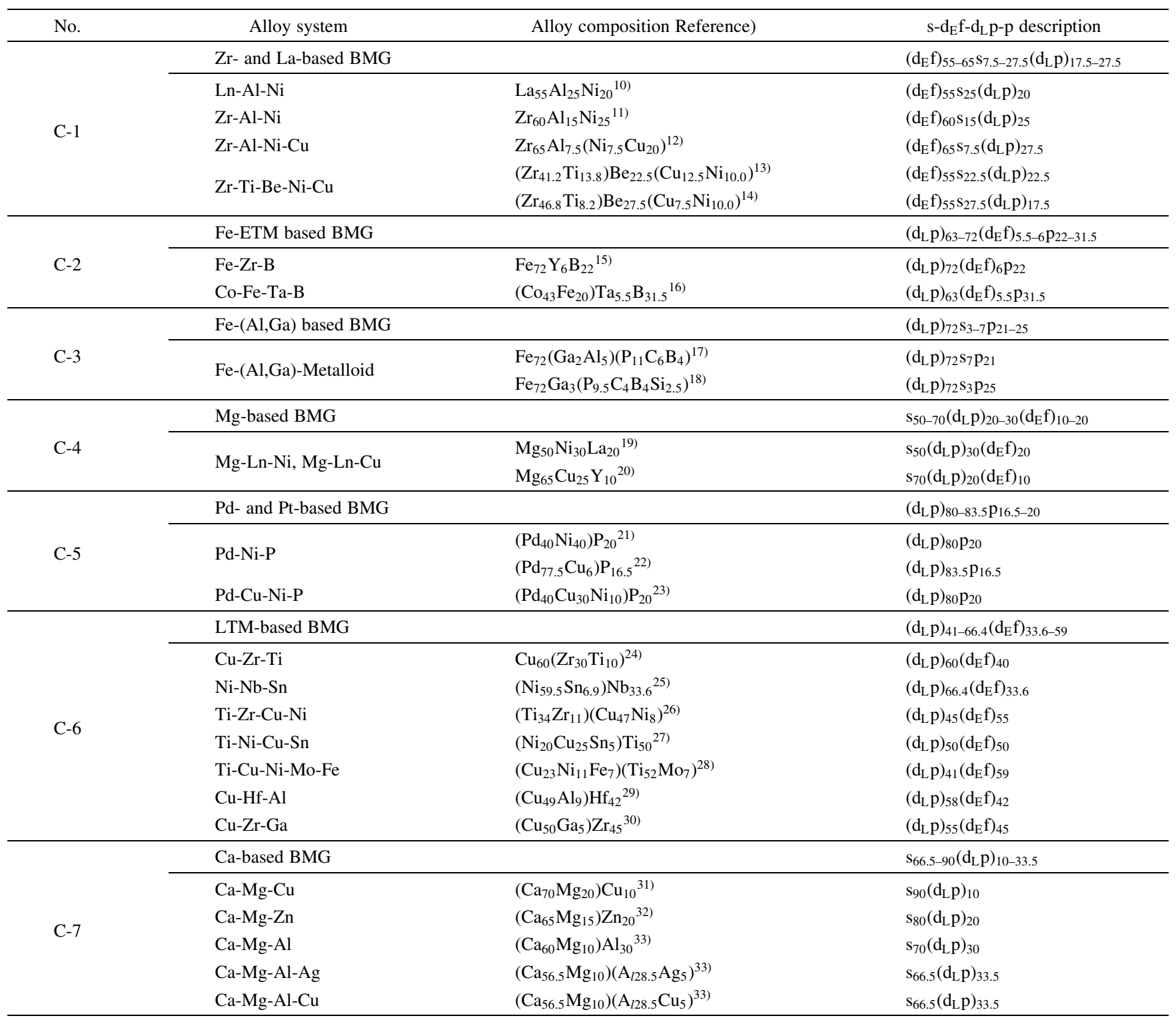

Figure 3(a) shows a projection of a tetrahedron composition diagram, which corresponds to the plane figure drawn in Fig. 2. The BMGs along with their reference numbers are plotted in the tetrahedron composition diagram in accordance with their $s-d_{E} f-d_{L} p-p$ descriptions shown in Table 4. Figure 3(b) shows the three-dimensional view of the composition diagram. The thin lines parallel to the coordinates of $\mathrm{s}-\mathrm{p}, \mathrm{p}-\mathrm{d}_{\mathrm{L}} \mathrm{p}, \mathrm{d}_{\mathrm{L}} \mathrm{p}-\mathrm{s}$, and so on in Fig. 3 are to guide the eye in order to evaluate the BMG compositions using the $s-d_{E} f-d_{L} p-$ $\mathrm{p}$ description. The thick gray curves, which connect the BMG plots, show the relationships of BMGs. Figure 3 can be regarded as a conventional tetrahedron composition diagram when treated as a quaternary alloy system, consisting of constituents from the s-, $d_{E} f-, d_{L} p-$ and p-constituent classes, which is exemplified by the $\operatorname{Mg}(\mathrm{s})-\mathrm{Zr}\left(\mathrm{d}_{\mathrm{E}} \mathrm{f}\right)-\mathrm{Fe}\left(\mathrm{d}_{\mathrm{L}} \mathrm{p}\right)-\mathrm{B}(\mathrm{p})$ system. In Fig. 3(b), the constituent classes of s-, $d_{E} f-, d_{L} p-$, and $\mathrm{p}$ - are placed at the vertices, BMGs, which belong to $\mathrm{C}-1$ to $\mathrm{C}-4,{ }^{10-20)}$ are plotted on the faces, and those belonging to
C-5 to C- ${ }^{21-33)}$ are plotted on the edges of the tetrahedron composition diagram. Accordingly, it is noted that the BMGs with reference numbers of 10 to 33 are plotted at the edges or on the faces in Fig. 3(b), although the tetrahedron composition diagram has the capacity for plots inside the diagram. The absence of BMGs inside $s-d_{E} f-d_{L} p-p$ tetrahedron composition diagram can be regarded as a general trend of currently known BMGs.

Figure 3 also provides other general trends for forming BMGs. As mentioned above, the composition band of the composition regions is formed as a thick curve in Fig. 3. This composition band tends to smoothly connect the composition regions of representative $\mathrm{BMGs}$ in the order of the reference number of BMGs: C- $6,{ }^{25-28)} \mathrm{C}-1,{ }^{12-14)} \mathrm{C}-4,{ }^{19,20)} \mathrm{C}-7,{ }^{31-33)}$ $\mathrm{C}-3,{ }^{17,18)} \mathrm{C}-5,{ }^{22,23)}$ and $\mathrm{C}-2 .{ }^{15,16)}$ This tendency to form a composition band indicates that there are general trends in the composition regions over the seven classes of BMG systems. The presence of the composition band is mainly due 

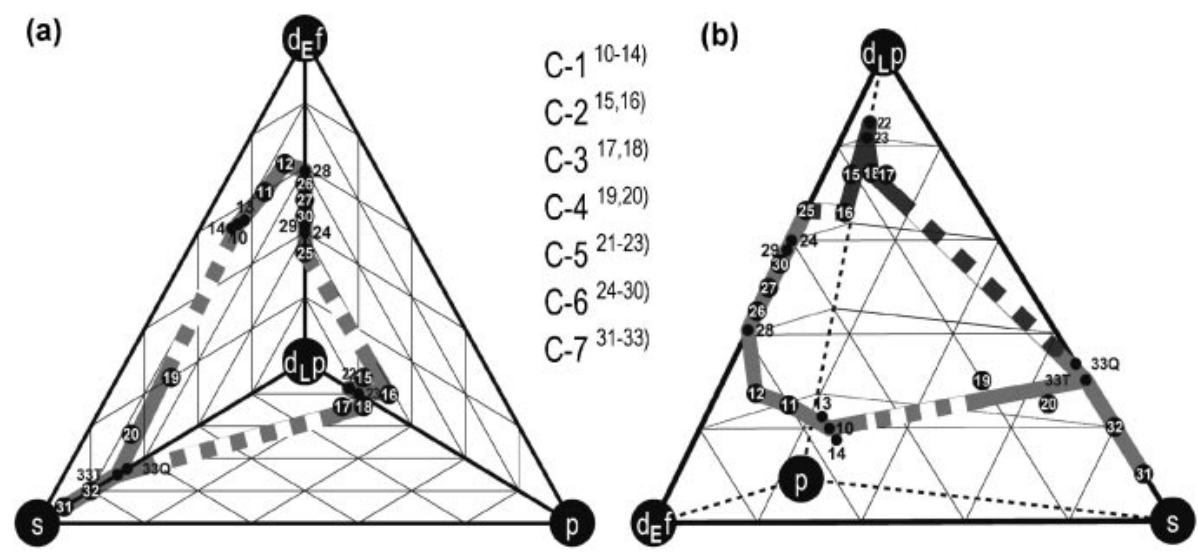

Fig. 3 s- $d_{E} f-d_{L} p-p$ Composition diagram, in its plane projection (a) and solid drawing (b) with plots of typical BMGs from the seven classes of the BMG system. The numbers 10-33 surrounded by small circles or typed near the plot correspond to the reference numbers. The thick gray curve, which connects the BMG compositions, is the composition band where BMGs are readily obtained. Figure 3(a) can be seen as a solid figure when $d_{L} p$ is placed under the page and placing the p-class of constituents in Fig. 3(b) under the page gives a clear implication of a solid figure. $\left(\mathrm{Pd}_{40} \mathrm{Ni}_{40}\right) \mathrm{P}_{20}{ }^{21)}$ is compensatory plotted with $\left(\mathrm{Pd}_{40} \mathrm{Cu}_{30} \mathrm{Ni}_{10}\right) \mathrm{P}_{20}{ }^{23)}$ due to the overlap in the s-d $\mathrm{d}_{\mathrm{E}} \mathrm{f}-\mathrm{d}_{\mathrm{L}} \mathrm{p}-\mathrm{p}$ description: $\left(\mathrm{d}_{\mathrm{L}} \mathrm{p}\right)_{80} \mathrm{p}_{20}$. The ternary system of $\mathrm{Ca}-\mathrm{Mg}-\mathrm{Cu}^{33)}$ and quaternary systems of $\mathrm{Ca}-\mathrm{Mg}-\mathrm{Al}-\mathrm{Ag}{ }^{33)}$ and $\mathrm{Ca}-\mathrm{Mg}-\mathrm{Al}-\mathrm{Cu}{ }^{33)}$ are distinguished as $33 T$ and $33 \mathrm{Q}$, respectively, based on the $s-d_{E} f-d_{L} p-p$ descriptions in Table 4 in order to avoid duplications in their reference number.

to the absence of BMGs plotted (1) on the $s-d_{E} f-p$ face, (2) on the $d_{E} f-d_{L} p$-p face inside of which the $d_{L} p$-composition is 70 at $\%$ or less, (3) on the $s-d_{E} f-d_{L} p$ face inside of which the $\mathrm{d}_{\mathrm{L}} \mathrm{p}$-composition is 30 at\% or more, and (4) due to the absence of BMGs plotted inside the $s-d_{L} p-p$ face, except for $\mathrm{Fe}-(\mathrm{Al}, \mathrm{Ga})$ based BMGs $(\mathrm{C}-3)$. In other words, this tendency indicates that BMGs can be formed by avoiding atomic pairs of $s-p$ and $d_{E} f-p$, which possess a covalent bond-like characteristic instead of a pure metallic bond.

Another trend for forming BMGs can be seen in the dense plots of compositions in different BMG classes. For instance, BMGs, which belong to $\mathrm{C}-2\left(\mathrm{Fe}_{72} \mathrm{Y}_{6} \mathrm{~B}_{22}{ }^{15}\right)$ and $\left(\mathrm{Co}_{43}\right.$ $\left.\left.\mathrm{Fe}_{20}\right) \mathrm{Ta}_{5.5} \mathrm{~B}_{31.5}{ }^{16)}\right)$, C-3 $\left(\mathrm{Fe}_{72}\left(\mathrm{Ga}_{2} \mathrm{Al}_{5}\right)\left(\mathrm{P}_{11} \mathrm{C}_{6} \mathrm{~B}_{4}\right)^{17)}\right.$ and $\mathrm{Fe}_{72^{-}}$ $\left.\mathrm{Ga}_{3}\left(\mathrm{P}_{9.5} \mathrm{C}_{4} \mathrm{~B}_{4} \mathrm{Si}_{2.5}\right)^{18)}\right)$, and $\mathrm{C}-5\left(\left(\mathrm{Pd}_{40} \mathrm{Ni}_{40}\right) \mathrm{P}_{20},{ }^{21)}\left(\mathrm{Pd}_{77.5^{-}}\right.\right.$ $\left.\mathrm{Cu}_{6}\right) \mathrm{P}_{16.5}{ }^{22)}$ and $\left.\left(\mathrm{Pd}_{40} \mathrm{Cu}_{30} \mathrm{Ni}_{10}\right) \mathrm{P}_{20}{ }^{23)}\right)$ are very close to each other in Fig. 3 near $\left(\mathrm{d}_{\mathrm{L}} \mathrm{p}\right)_{80} \mathrm{p}_{20}$, although the main constituents are different: Pd- and Pt-based BMGs (C-5) and $\mathrm{Fe}$ based BMGs (C-2 and C-3). Furthermore, $\left.\mathrm{La}_{55} \mathrm{Al}_{25} \mathrm{Ni}_{20},{ }^{10}\right)$ $\left(\mathrm{Zr}_{41.2} \mathrm{Ti}_{13.8}\right) \mathrm{Be}_{22.5}\left(\mathrm{Cu}_{12.5} \mathrm{Ni}_{10.0}\right),{ }^{13)}$ and $\left(\mathrm{Zr}_{46.8} \mathrm{Ti}_{8.2}\right) \mathrm{Be}_{27.5^{-}}$ $\left(\mathrm{Cu}_{7.5} \mathrm{Ni}_{10.0}\right)^{14)}$ are also close together in the diagram. The former and latter are regarded as Metal-Metalloid $\mathrm{BMG}^{3)}$ and $\mathrm{Zr}$ - or La-based BMG, respectively. Each type of BMG has an independent number of constituents. Thus, the $s-d_{E} f-$ $\mathrm{d}_{\mathrm{L}} \mathrm{p}$-p descriptions in Table 4 , and the resulting plots in Fig. 3 are helpful from a chemical point of view for evaluating the similarity in BMG compositions of the constituents.

\section{Discussion}

The discussion is organized as follows: First, factors that support $\mathrm{Al}$ and $\mathrm{Ga}$ as constituents of the s-class are discussed in Sections 4.1 and 4.2. Then the relationships of BMGs obtained in our previous studies ${ }^{4,5)}$ are introduced in Section 4.3. These relationships are used in Section 4.4. to determine the status of $\mathrm{Al}$ and $\mathrm{Ga}$ in the BMG composition environment. Finally, the significance of the tetrahedron composition diagram is discussed in Section 4.5.

\subsection{Electronegativity}

The electronegativities $(\chi)$ of $\mathrm{Al}$ and $\mathrm{Ga}$ are 1.5 and 1.6, respectively and are shown in Fig. 1, which is from the literature. ${ }^{34)}$ On the other hand, the range of $\chi$ for s-block elements is $\chi \leq 1.0(\mathrm{Ca}, \mathrm{Sr}), 1.2(\mathrm{Mg})$, and $1.5(\mathrm{Be})$, while $\chi$ for VIII to VIB metallic elements is $1.5(\mathrm{Al}), 1.6(\mathrm{Ga}, \mathrm{Zn})$ and $2.4(\mathrm{Au})$. Accordingly, $\chi$ of $\mathrm{Al}$ is the same as that of $\mathrm{Be}$, which has the largest $\chi$ value among the s-block elements, and Ga has the next smallest $\chi$ value among the III to VIB metallic elements. Thus, an intermediate value of $\chi$, which ranges 1.5 to 1.6 , allows $\mathrm{Al}$ and $\mathrm{Ga}$ to be treated as constituents of the s-class when they are involved in BMGs.

\subsection{Aspects for forming ionic bonds}

The following aspects, which are usually discussed when forming ionic bonds, must be considered in order to understand why $\mathrm{Al}$ and $\mathrm{Ga}$ can be constituents of the s-class, even though they have a metallic bonding nature in BMGs.

\subsubsection{Diagonal relationships in the periodic table ${ }^{35)}$}

The diagonal relationships in the periodic table support the similarity in the characteristics between $\mathrm{Be}$ and $\mathrm{Al} .^{35)}$ This relationship, which can be applied to sets of atomic pairs such as $\mathrm{Li}$ and $\mathrm{Mg}, \mathrm{Be}$ and $\mathrm{Al}$, and $\mathrm{B}$ and $\mathrm{Si}$, are due to the comparative ease in the ionization of elements that are diagonal on the periodic table, which results from the counteracting effects of the increased ease in the ionization down a group and the decreased in the ease of ionization from left to right in the periodic table. Thus, the diagonal relationship between $\mathrm{Be}$ and $\mathrm{Al}$ indicates that these elements are similar because they both are ions with the same ease. ${ }^{35)}$ 4.2.2 Inert pair effect ${ }^{35)}$

This sub-section evaluates the validity of distinguishing $\mathrm{Al}$ and $\mathrm{Ga}$ from other p-block metallic elements using the inert pair effect to treat $\mathrm{Al}$ and $\mathrm{Ga}$ as part of the s-constituent class. The inert pair effect addresses the possibility of an element, which belongs to a heavier sub-group B in the periodic table, to form ions other than that with an 18-electron group structure, which is the expected ionic structure. ${ }^{35)}$ These 


\begin{tabular}{|c|c|c|c|c|c|c|}
\hline \multirow{2}{*}{\multicolumn{2}{|c|}{ 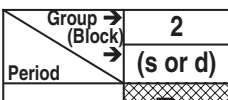 }} & 3 & 4 & 5 & 6 & 7 \\
\hline & & \multicolumn{5}{|c|}{ (p) } \\
\hline 2 & Be & B & C & $\mathbf{N}$ & 0 & $F$ \\
\hline 3 & 1.9 & Al & Si & P & $S$ & $\mathrm{CI}$ \\
\hline 4 & $\mathrm{Zn}$ & Ga & $\mathrm{Ge}$ & As & $\mathrm{Se}$ & $\mathrm{Br}$ \\
\hline 5 & cd & $\mathrm{in}$ & Sin & sib & $\mathrm{Te}$ & 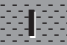 \\
\hline 6 & $H_{10}$ & $\mathrm{II}$ & $\mathrm{pb}$ & $\mathrm{Bi}$ & $\mathbf{P O}$ & $\mathrm{At}$ \\
\hline
\end{tabular}

\begin{tabular}{|l|l}
\hline & Metalloid (non-metallic element) \\
inert pair effect type \\
$x$ \\
s-block element \\
d-block element
\end{tabular}

Fig. 4 Part of the short-periodic table summarized with the group, block, and period. ${ }^{35)} \mathrm{A}$ thick line separates the upper-left and lower-right types. The elements in the lower-right types are the elements in which inert pair effect works. ${ }^{35)}$ Among these elements, $\mathrm{Al}$ and $\mathrm{Ga}$ are the only p-block metallic elements that are independent of inert pair effect.

unexpected ions have a charge of two units less than that of the expected ions. For instance, although $\mathrm{Pb}^{4+}$ is predicted from the periodic table, $\mathrm{Pb}^{2+}$ is more stable. This $\mathrm{Pb}$ example differs from $\mathrm{Al}$ and $\mathrm{Ga}$, which belong to lighter sub-group $\mathrm{B}$, because $\mathrm{Al}$ and $\mathrm{Ga}$ form $\mathrm{Al}^{3+}$ and $\mathrm{Ga}^{3+}{ }^{36)}$ In general, the inert pair effect works for p-block elements in the lower-right part of the periodic table $(\mathrm{Cl}, \mathrm{As}, \mathrm{Se}, \mathrm{Br}, \mathrm{In}, \mathrm{Sn}, \mathrm{Sb}, \mathrm{Te}, \mathrm{I}$, $\mathrm{Hg}, \mathrm{Tl}, \mathrm{Pb}$, and $\mathrm{Bi})^{35)}$ as shown in Fig. 4. Al and $\mathrm{Ga}$ are highlighted from the other metallic elements in Fig. 4 because $\mathrm{Al}$ and $\mathrm{Ga}$ are the only p-block elements with a non-inert pair type effect. $\mathrm{Be}, \mathrm{Mg}, \mathrm{Zn}$, and $\mathrm{Cd}$ also display the non-inert pair effect type, but $\mathrm{Be}$ and $\mathrm{Mg}$ belong to the sblock, while $\mathrm{Zn}$ and $\mathrm{Cd}$ belong to the d-block.

\subsection{Relationship between the main constituent and the classification of $\mathrm{BMGs}^{5}$}

The following relationships for BMGs were obtained in our previous ${ }^{5)}$ and the present study was partially used to determine the status of $\mathrm{Al}$ and $\mathrm{Ga}$ in Section 4.4. It has been reported $^{5)}$ that BMGs found to date exhibit relationships between the BMG system class and the type of main constituent and the relative atomic radius of the main constituents. For instance, the main constituents of ternary C-1 (Zr- and La-based), C-5 (Pd- and Pt-based) and C-7 (Cabased), ternary $\mathrm{C}-2$ (Fe-based) and $\mathrm{C}-4$ (Mg-based), and ternary C-6 (LTM-based) BMGs are the largest, intermediate, and smallest atomic radius, respectively. In addition, BMGs that belong to $\mathrm{C}-6$ change their main constituent with the atomic radius from the smallest to the larger size as the glass-forming ability increases by multi-component alloying of ternary alloys. The minimum number of constituent classes necessary to form BMGs are two for C-5 to C-7 and three for the others (C-1 to $\mathrm{C}-4)$, which are identical to the results obtained in the present study (Fig. 2).

\subsection{Determining the status of $\mathrm{Al}$ and $\mathrm{Ga}$ in a BMG composition environment}

This sub-section discusses the status of $\mathrm{Al}$ and $\mathrm{Ga}$ in
BMGs in terms of the composition environment of the main constituent in the following four cases: (1) a $d_{E} f-r i c h$ environment (C-1), (2) an s-rich environment (C-7), (3) a $\mathrm{d}_{\mathrm{L}} \mathrm{p}$-rich without a $\mathrm{p}$ environment (C-6), and (4) a $\mathrm{d}_{\mathrm{L}} \mathrm{p}$-rich with a $\mathrm{p}$ environment (C-3). We selected these four cases from Tables 3 and 4, which show that $\mathrm{Al}$ and $\mathrm{Ga}$ are constituents of BMGs belonging to C-1, C-3, C-6, and C-7, and that the main constituent, which is designated with a bold letter in Table 3 for these classes of BMGs, is a constituent in the $d_{E} f-(C-1), d_{L} p-(C-3), d_{L} p-(C-6)$ and $s-(C-7)$-constituent classes. Furthermore, Table 3 shows that the presence of a metalloid ( $\mathrm{P}, \mathrm{C}, \mathrm{P}, \mathrm{Si}, \mathrm{Ge})$ in the p-class of constituents helps to distinguish the BMGs in $\mathrm{C}-3$ from those in $\mathrm{C}-6$ because both BMGs can be described as $\mathrm{d}_{\mathrm{L}} \mathrm{p}$-rich environments. In particular, we discuss the status of the s-constituent class of $\mathrm{Al}$ and $\mathrm{Ga}$, which appears in (1) a $\mathrm{d}_{\mathrm{E}} \mathrm{f}$-rich environment (C-1) and (4) a $d_{L}$ p-rich with a p composition environment (C-3), because the status of the s-constituent class for $\mathrm{Al}$ and $\mathrm{Ga}$ contradicts the fact that $\mathrm{Al}$ and $\mathrm{Ga}$ are p-block elements in the periodic table. In the next sub-section, we discuss this by hypothetically assuming that $\mathrm{Al}$ and $\mathrm{Ga}$ are constituents of the $\mathrm{d}_{\mathrm{L}} \mathrm{p}$-class, which is the opposite treatment for BMGs in C1 and C-3 shown in Table 3 .

\subsection{1 $d_{E}$ f-Rich environment (C-1)}

Assuming $\mathrm{Al}$ is in the $\mathrm{d}_{\mathrm{L}} \mathrm{p}$-constituent class for a BMG in $\mathrm{C}-1$ reduces the minimum number of constituents from three to two. For instance, $\mathrm{Zr}-\mathrm{Al}-\mathrm{Ni}$ in Table 3 would be described as $\left(d_{E} f-d_{L} p\right)$ instead of $\left(s-d_{E} f-d_{L} p\right)$ due to the shift in the constituent class of $\mathrm{Al}$ from $\mathrm{s}-$ to $\mathrm{d}_{\mathrm{L}} \mathrm{p}-$. This shift is inconsistent with the relationships obtained in the previous study, which is described in Section 4.3 and states that the minimum number of constituent classes for BMGs in C-1 is three. Moreover, assuming $\mathrm{Al}$ is a constituent in the $\mathrm{d}_{\mathrm{L}} \mathrm{p}$ constituent class would make $\mathrm{Zr}_{60} \mathrm{Al}_{15} \mathrm{Ni}_{25}$ (Table 4) part of the $d_{E} f-d_{L} p$ class of BMG $(C-6)$, but would maintain that the main constituent is $\mathrm{Zr}$, which has the largest atomic radius ( $\mathrm{Zr}: 0.162 \mathrm{~nm}, \mathrm{Al}: 0.143 \mathrm{~nm}, \mathrm{Ni}: 0.125 \mathrm{~nm}^{5)}$ ). This finding is inconsistent with the relationship that the main constituent of BMGs in C-6 is the constituent with the smallest atomic radius. These counter-examples support the status of $\mathrm{Al}$ as a constituent of the s-constituent class.

\subsection{2 $d_{L} p$-Rich with a environment (C-3)}

As shown in Table 4, $\mathrm{Fe}_{72}\left(\mathrm{Ga}_{2} \mathrm{Al}_{5}\right)\left(\mathrm{P}_{11} \mathrm{C}_{6} \mathrm{~B}_{4}\right)^{17)}$ and $\mathrm{Fe}_{72} \mathrm{Ga}_{3}\left(\mathrm{P}_{9.5} \mathrm{C}_{4} \mathrm{~B}_{4} \mathrm{Si}_{2.5}\right)^{18)}$ are the BMGs that belong to $\mathrm{C}-3$. The constituents of these BMGs indicate that $\mathrm{Ga}$ is the primary constituent and $\mathrm{Al}$ is the supplemental constituent because $\left.\mathrm{Fe}_{72} \mathrm{Ga}_{3}\left(\mathrm{P}_{9.5} \mathrm{C}_{4} \mathrm{~B}_{4} \mathrm{Si}_{2.5}\right)^{18}\right)$ is formed in the BMG without Al. Accordingly, in this sub-section, the $\mathrm{Fe}_{72} \mathrm{Ga}_{3}-$ $\left(\mathrm{P}_{9.5} \mathrm{C}_{4} \mathrm{~B}_{4} \mathrm{Si}_{2.5}\right)^{18)} \mathrm{BMG}$ is initially discussed, and then the status of $\mathrm{Al}$ in BMGs is treated the same as BMGs with $\mathrm{Ga}$ for the $\mathrm{Fe}_{72}\left(\mathrm{Ga}_{2} \mathrm{Al}_{5}\right)\left(\mathrm{P}_{11} \mathrm{C}_{6} \mathrm{~B}_{4}\right)$ BMG because the present approach does not allow the statuses of $\mathrm{Al}$ and $\mathrm{Ga}$ to be separately discussed in the $\mathrm{Fe}_{72}\left(\mathrm{Ga}_{2} \mathrm{Al}_{5}\right)\left(\mathrm{P}_{11} \mathrm{C}_{6} \mathrm{~B}_{4}\right) \mathrm{BMG}$.

In Table 3, assuming $\mathrm{Ga}$ as an s-constituent class instead of as a constituent in the $\mathrm{d}_{\mathrm{L}}$ p-class makes $\mathrm{Fe}_{72} \mathrm{Ga}_{3}\left(\mathrm{P}_{9.5^{-}}\right.$ $\mathrm{C}_{4} \mathrm{~B}_{4} \mathrm{Si}_{2.5}$ ) BMG, which would be described as $\mathrm{d}_{\mathrm{L}} \mathrm{p}-\mathrm{p}(\mathrm{C}-5)$ while maintaining the main constituent of $\mathrm{Fe}$, which has an intermediate atomic radius (Fe: $0.124 \mathrm{~nm}, \mathrm{Ga}: 0.124 \mathrm{~nm}, \mathrm{P}$ : $0.109 \mathrm{~nm}, \mathrm{C}: 0.077 \mathrm{~nm}, \mathrm{~B}: 0.090 \mathrm{~nm}^{5)}$ ). This result weakly affirms (5) the relationship of BMGs mentioned in Section 
4.3, which indicates that the main constituent of BMGs in C5 is the constituent with the largest atomic radius, because $\mathrm{Fe}$ and $\mathrm{Ga}$ have the same atomic radius. However, the $\mathrm{BMG}$ of $\mathrm{Fe}_{72}\left(\mathrm{Ga}_{2} \mathrm{Al}_{5}\right)\left(\mathrm{P}_{11} \mathrm{C}_{6} \mathrm{~B}_{4}\right)$ contradicts the relationship mentioned in Section 4.3 with respect to the main constituent because $\mathrm{Al}$, which has the largest atomic radius of $0.143 \mathrm{~nm}$, is not the main constituent in the $\mathrm{Fe}_{72}\left(\mathrm{Ga}_{2} \mathrm{Al}_{5}\right)\left(\mathrm{P}_{11} \mathrm{C}_{6} \mathrm{~B}_{4}\right)$ BMG. Thus, we concluded that $\mathrm{Al}$ and $\mathrm{Ga}$ are in the sconstituent class.

\subsection{3 s-Rich (C-7)and $d_{L} p$-rich without a p environment (C-6)}

As shown in Table 3, Al and Ga in BMGs in C-7 and C-6 are part of the $d_{L}$ p-constituent class, which is expected because $\mathrm{Al}$ and $\mathrm{Ga}$ are p-block elements. Thus, in this subsection we explore this assignment by giving $\mathrm{Al}$ and $\mathrm{Ga}$ the hypothetical status as constituents in the s-constituent class BMGs in C-7 and C-6.

This assumption causes a discrepancy for the $\left(\mathrm{Ca}_{60}-\right.$ $\left.\mathrm{Mg}_{10}\right) \mathrm{Al}_{30}$ BMG (C-7), which is described as $\mathrm{s}_{70}\left(\mathrm{~d}_{\mathrm{L}} \mathrm{p}\right)_{30}$ in Table 4 because the hypothesis would make $\left(\mathrm{Ca}_{60} \mathrm{Mg}_{10}\right)$ $\mathrm{Al}_{30}$ BMG part of the $\mathrm{s}_{100}$ constituent class. However, this type of BMG has yet to be discovered. On the other hand, applying this hypothesis to $\left(\mathrm{Cu}_{49} \mathrm{Al}_{9}\right) \mathrm{Hf}_{42}$ and $\left(\mathrm{Cu}_{50} \mathrm{Ga}_{5}\right) \mathrm{Zr}_{40}$ BMGs (C-6), which are in the $\left(\mathrm{d}_{\mathrm{L}} \mathrm{p}\right)_{58}\left(\mathrm{~d}_{\mathrm{E}} \mathrm{f}\right)_{42}$ and $\left(\mathrm{d}_{\mathrm{L}} \mathrm{p}\right)_{55^{-}}$ $\left(d_{E} f\right)_{45}$ classes, respectively, in Table 4 would convert the classes to $s_{9}\left(d_{L} p\right)_{49}\left(d_{E} f\right)_{42}$ and $s_{5}\left(d_{L} p\right)_{50}\left(d_{E} f\right)_{45}$, respectively. Thus, BMGs in C-1 and C-4 should be $s-d_{L} p-d_{E} f$, as shown in Table 3, with the main constituent, $\mathrm{Cu}\left(\mathrm{d}_{\mathrm{L}} \mathrm{p}\right)$, unchanged. However, this contradicts the trend of BMGs described in Section 4.3, which is that the main constituents in C-1 and C$4 \mathrm{BMGs}$ have the largest atomic radius. These examples of BMGs in $\mathrm{C}-7$ and $\mathrm{C}-6$ reveal that the hypothesis that $\mathrm{Al}$ and $\mathrm{Ga}$ are constituents in the s-constituent class BMGs in C-7 and C- 6 does not satisfy the results obtained in the framework of previous studies. ${ }^{4,5)}$

\subsection{Significance of the tetrahedron composition dia- gram}

As described in Section 3, the $s-d_{E} f-d_{L} p-p$ tetrahedron composition diagram visually extracts similarities in the BMGs. For instance, it clearly shows that the BMGs are not formed in the $s-d_{E} f-p$ face of the diagram. Furthermore, the BMGs that belong to $\mathrm{C}-2, \mathrm{C}-3, \mathrm{C}-5$ are plotted near the composition of $\left(d_{L} p\right)_{80} p_{20}$ and are independent of the number of constituents necessary to form BMGs. Another similarity in the plots is exemplified by $\mathrm{La}_{55} \mathrm{Al}_{25} \mathrm{Ni}_{20},{ }^{10)}\left(\mathrm{Zr}_{41.2} \mathrm{Ti}_{13.8}\right)$ $\mathrm{Be}_{22.5}\left(\mathrm{Cu}_{12.5} \mathrm{Ni}_{10.0}\right){ }^{13)}$ and $\left(\mathrm{Zr}_{46.8} \mathrm{Ti}_{8.2}\right) \mathrm{Be}_{27.5}\left(\mathrm{Cu}_{7.5} \mathrm{Ni}_{10.0}\right) .{ }^{14)}$ These examples imply the importance of $\mathrm{BMG}$ research on the different classes of BMGs as well as precise research for new alloy systems.

Furthermore, the discussion explored in Section 4.4 provides four types of composition environments for $\mathrm{Al}$ and $\mathrm{Ga}$ in BMGs: $\mathrm{d}_{\mathrm{E}}$ f-rich $(\mathrm{C}-1)$, s-rich $(\mathrm{C}-7), \mathrm{d}_{\mathrm{L}} \mathrm{p}$-rich without a p-composition environment $(\mathrm{C}-6)$, and $\mathrm{d}_{\mathrm{L}} \mathrm{p}$-rich with a p environment (C-3). The results show that $\mathrm{Al}$ and $\mathrm{Ga}$ can be treated as constituents of the s-constituent class BMGs in a $d_{E}$ f-rich $(C-1)$ and $d_{L}$ p-rich with a p-composition environment (C-3), but can be regarded as part of the $d_{L} p-$ constituent class in BMGs in an s-rich (C-7) and a $d_{L} p$-rich without a p-composition environment (C-6). Thus, $\mathrm{Al}$ and $\mathrm{Ga}$ belong to the p-block elements as free atoms, but they lose their $\mathrm{p}$ orbital characteristics when they are BMG constituents in the following cases: (1) when $\mathrm{Al}$ and $\mathrm{Ga}$ are in a $\mathrm{d}_{\mathrm{E}} \mathrm{f}-$ rich $(\mathrm{C}-1)$ composition environment and are surrounded by solvent in the $\mathrm{d}_{\mathrm{E}}$ f class, and (2) when $\mathrm{Al}$ and $\mathrm{Ga}$ are in a $\mathrm{d}_{\mathrm{L}} \mathrm{p}-$ rich with a p-(C-3) composition environment where a metalloid ( $\mathrm{P}, \mathrm{C}, \mathrm{B}, \mathrm{Si}, \mathrm{Ge})$ is also a constituent with $\mathrm{Al}$ and $\mathrm{Ga}$. This interpretation exhibits the attractive and the repulsive interactions of $\mathrm{Al}$ and $\mathrm{Ga}$, and the main constituent of BMGs. These observations should be related to the bonding nature of $\mathrm{Al}$ and $\mathrm{Ga}$ in each composition environment, which is governed by the main constituent, and should provide information on the electron structure of the BMGs.

Thus, the $s-d_{E} f-d_{L} p-p$ composition diagram is of great importance for analyzing the characteristics of BMGs due to its simplicity and applicability to any multi-component alloy system. Furthermore, the composition diagram has potential for analyzing other non-equilibrium materials, such as quasicrystalline alloys and equilibrium alloys that contain intermetallic compounds. Combining the analyses of these metallic materials along with the $s-d_{E} f-d_{L} p-p$ tetrahedron composition diagram should open a new approach for a better understanding of metallic materials.

\section{Conclusion}

The formation of bulk metallic glasses (BMGs) has been analyzed based on a chemistry approach assisted with the electron characteristics of the constituent elements. BMGs found to date have been classified into seven classes, which are comprised of constituent classes, s-, $d_{E} f_{-}, d_{L} p-$, and p-, where these symbols are abbreviations for s-block elements $(s)$, early transition metals and f-block elements $\left(d_{E} f\right)$, late transition and p-block metals $\left(d_{L} p\right)$, and metalloids $(p)$. It is assumed that $\mathrm{Al}$ and $\mathrm{Ga}$ may be a constituent for either the sor $\mathrm{d}_{\mathrm{L}} \mathrm{p}$-constituent class in order to reasonably plot the compositions of the BMG seven classes (C-1-C-7) in the s$d_{E} f-d_{L} p-p$ tetrahedron composition diagram. This supplemental approach, which considers the electron characteristics of the constituent elements associated with chemistry approach, solves the discrepancy in the classifications of BMGs in our previous studies with respect to Be-containing Zr-based BMGs, which were previously classified into a group other than a Zr-based system. The $s-d_{E} f-d_{L} p-p$ tetrahedron composition diagram shows that a composition band exists in composition regions over the seven BMG classes. A prototype of the composition criteria to form BMGs on the basis of the chemistry approach has been obtained as the composition band of BMGs in a s-d $d_{E} f-d_{L} p-p$ tetrahedron diagram with a topological simplicity. This diagram is widely applicable to any multi-component alloy system and can be analyzed from the bonding nature of the atomic pairs.

\section{REFERENCES}

1) A. Inoue: Bulk amorphous alloys: Preparation and Fundamental Characteristics, (Trans Tech Publications, Switzerland, 1998) pp. 1.

2) J. Hafner: Phys. Rev. B. 21 (1980) 406-426.

3) T. Masumoto: Proc. 4th Int. Conf. on Rapidly Quenched Metals (The 
Japan Inst. Metals, 1982) pp. 5-10.

4) A. Inoue: Acta Mater. 48 (2000) 279-306.

5) A. Takeuchi and A. Inoue: Mater. Trans. 46 (2005) 2817-2829.

6) D. B. Miracle: Nature Mater. 3 (2004) 697-702.

7) S. Ranganathan, B. S. Murty, A. Takeuchi and A. Inoue: private communication.

8) The structures of binary compounds (Elsevier Science Publishers B.V., The Netherlands, 1989) pp. 1.

9) X. F. Zhang, Y. M. Wang, J. B. Qiang, Q. Wang, D. H. Wang, D. J. Li, C. H. Shek and C. Dong: Intermetallics 12 (2004) 1275-1278.

10) A. Inoue, T. Zhang and T. Masumoto: Mater. Trans., JIM 30 (1989) 965-972.

11) A. Inoue, T. Zhang and T. Masumoto: Mater. Trans., JIM 31 (1990) 177-183.

12) T. Zhang, A. Inoue and T. Masumoto: Mater. Trans., JIM 32 (1991) 1005-1010.

13) A. Peker and W. L. Johnson: Appl. Phys. Lett. 63 (1993) 2342-2344.

14) W. L. Johnson: MRS Bull. 24 (1999) 42-56.

15) C. Y. Lin, H. Y. Tien and T. S. Chin: Appl. Phys. Lett. 86 (2005) 162501.

16) A. Inoue, B. L. Shen, H. Koshiba, H. Kato and A. R. Yavari: Acta Mater. 52 (2004) 1631-1637.

17) A. Inoue and J. S. Gook: Mater. Trans., JIM 36 (1995) 1180-1183.

18) B. L. Shen and A. Inoue: Mater. Trans. 43 (2002) 1235-1239.

19) A. Inoue, M. Kohinata, A. P. Tsai and T. Masumoto: Mater. Trans., JIM 30 (1989) 378-381.

20) A. Inoue, A. Kato, T. Zhang, S. G. Kim and T. Masumoto: Mater.
Trans., JIM 32 (1991) 609-616.

21) H. W. Kui, A. L. Greer and D. Turnbull: Appl. Phys. Lett. 65 (1984) 615-616.

22) H. S. Chen: Acta Metall. 22 (1974) 1505-1511.

23) A. Inoue, N. Nishiyama and T. Matsuda: Mater. Trans., JIM 37 (1996) $181-184$.

24) A. Inoue, W. Zhang, T. Zhang and K. Kurosaka: Mater. Trans. 42 (2001) 1149-1151.

25) H. Choi-Yim, D. H. Xu and W. L. Johnson: Appl. Phys. Lett. 82 (2003) 1030-1032.

26) Y. C. Kim, W. T. Kim and D. H. Kim: Mater. Sci. Eng. A 375-377 (2004) 127-135.

27) T. Zhang and A. Inoue: Mater. Trans., JIM 39 (1998) 1001-1006.

28) N. Nishiyama, K. Amiya and A. Inoue: Mater. Trans. 45 (2004) 12451250.

29) P. Jia, H. Guo, Y. Li, J. Xu and E. Ma: Scrip. Mater. 54 (2006) 21652168.

30) W. Zhang and A. Inoue: Mater. Trans. 45 (2004) 532-535.

31) K. Amiya and A. Inoue: Mater. Trans. 43 (2002) 81-84.

32) E. S. Park and D. H. Kim: J. Mater. Res. 19 (2004) 685-688.

33) F. Q. Guo, S. J. Poon and G. J. Shiflet: Appl. Phys. Lett. 84 (2004) 3739.

34) G. Burns: Solid State Physics, Academic Press Inc (1985) p. 177.

35) G. I. Brown: A new guide to modern valency theory, London, (Longman Group Ltd, 1967), p. 1.

36) F. A. Cotton, G. Wilkinson and P. L. Gauss: Basic inorganic chemistry, New York, (John Wiley \& Sons Inc, 1995), p. 261.

\section{Appendix}

Table A.1 Symbols used in the previous studies, ${ }^{2,4,5)}$ their implication, representative constituents, and reference number.

\begin{tabular}{|c|c|c|c|}
\hline Symbol & Implication & Representative constituents & Reference \\
\hline S & Simple Metal & $\mathrm{Be}, \mathrm{Mg}, \mathrm{Al}, \mathrm{Ca}, \mathrm{Zn}$ & 2) \\
\hline $\mathrm{T}$ & Transition Metal & $\mathrm{Fe}, \mathrm{Ni}, \mathrm{Cu}, \mathrm{Nb}, \mathrm{W}, \mathrm{Rh}, \mathrm{Ta}, \mathrm{Ir}, \mathrm{Pd}$ & 2) \\
\hline $\mathrm{R}$ & $\underline{\text { Rare-Earth Metal }}$ & $\mathrm{La}, \mathrm{Ce}, \mathrm{Gd}$ & 2) \\
\hline ETM & Early Transition Metal & IIIA-VIIA metals & $4,5)$ \\
\hline LTM & Late Transition Metal & VIII-IIB metals & $4,5)$ \\
\hline $\mathrm{Ln}$ & Lanthanide Metal & $\mathrm{La}$ to $\mathrm{Yb}$ & $4,5)$ \\
\hline Simple Metal & - & $\mathrm{Be}, \mathrm{Mg}$ & 4) \\
\hline Metalloid & - & $\mathrm{B}, \mathrm{C}, \mathrm{Si}, \mathrm{P}, \mathrm{Ge}$ & $4,5)$ \\
\hline IIA & Alkaline Earth Metals, IIA Metals & $\mathrm{Be}, \mathrm{Mg}, \mathrm{Ca}$ & 5) \\
\hline BM & IIIB-VIB Metals & - & 5) \\
\hline
\end{tabular}

Table A.2 Symbols and terms used in the present study and their explanation.

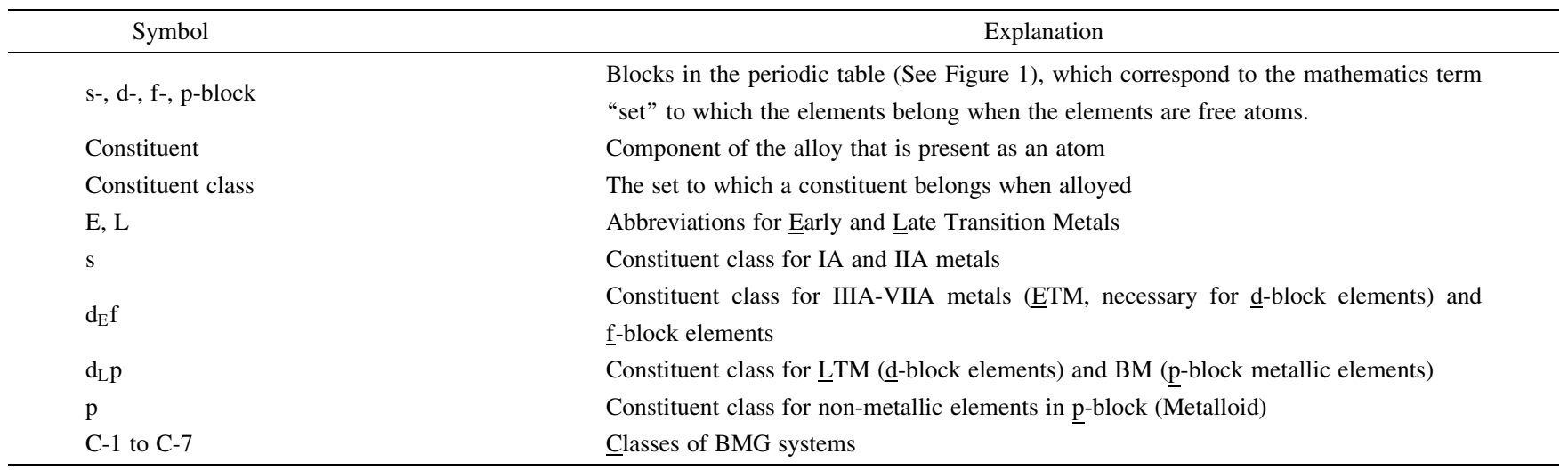

